\title{
Research on the Intellectual Property Protection of Cyber Source Based on Resource Utilization
}

\author{
Qian Gao \\ Sichuan electric vocational and technical college supervision department, Chengdu 610071, China \\ paperiset@163.com
}

Keywords: Intellectual property protection, Resource utilization, Cyber source,

\begin{abstract}
Based on the background of the current network era, this paper researched the problems on China's current network of intellectual property rights protection system which cannot be ignored, affecting the healthy development of the network, the right to make a lot of people have suffered losses, it is also unable to receive due compensation, leading to a social contradictions increasingly prominent influence of a socialist harmonious society building process, and therefore, choose a topic for research papers not only is of great practical significance, but also has great theoretical significance. Finally, the paper gives some basic suggestions on the intellectual property protection of cyber source based on resource utilization
\end{abstract}

\section{Introduction}

Since entering the 21st century, with the globalization of the world economy and speeding up the process of the rapid development of science and technology, as an encouragement and protection of innovation, the promotion of human social progress and economic development in the legal system, the intellectual property system in economic and social activities upgrade the status of historical, intellectual property protection by the international community wide attention, and for the protection of intellectual property awareness of the network, even to a later, the universal network manifests itself slowly. This paper establishes and improves a network information system for the protection of intellectual property goals, focusing on how better to create a network for the healthy development of a benign cycle, and the living environment of fair competition, in order to enhance network reliability, and the use of the information owner formed between communicators, as well as a truly fair, open, safe, friendly, interaction and mutual trust, and the exchange of information and research network platform [1].

With the rapid development of Internet technology and the number of Internet users continue to increase, the Internet has brought us convenience, it also brings problems. Compared to traditional intellectual property rights, the network intellectual property combines the two characteristics of network technology and intellectual property [2]. These characteristics break the proprietary, regional and timing characteristics of the traditional intellectual property rights. People's intelligence outcome can be propagated to all over the world only if the place is covered with Internet. The resulting intellectual property rights infringement cases has broader, shorter, and more infringer features, these infringement cases become more frequent, various types of infringement means endless, more and more rights have been infringed. As there are governance vulnerabilities of the Internet and loopholes in the law, the current legislation cannot keep up the pace of development of computer network technology, it makes it is difficult to trace the responsibility of the infringer [3]. The equity interests are not duly protected and violations of intellectual property extends beyond the individual, many international big companies get stuck, As the network intellectual property rights are not well protected, leading to more infringement and is bound to affect the development of the Internet. Now, the country too much emphasis on government control to neglect the development and improvement of the networking industry, the relevant departments of the network protection of intellectual property has develop a series of rules and regulations, but these are low, and lack of authoritative, systematic, and coordination, the number of regulations on management of the government is much more than the 
NPC's legislative [4]. In legislative process, the lack of democratic participation led to many loopholes in the management and the lack of legal. Therefore, legislation should be strengthened to establish a network of intellectual property rights regulatory agencies to strengthen links with the international protection of intellectual property department, learning the advanced experience of foreign network of IPR cases, improve the awareness of intellectual property rights of Internet users and create a harmonious Internet environment [5].

\section{The Network Information Resource Utilization in Major Violations}

World Intellectual Property Organization, the European Union, the United States, Japan, Australia and other countries have begun to digital transmission system, the impact of copyright discussion, and discussion with the technology is gradually in-depth. Although the right to peruse the Internet to connect users to the site in the works, which the viewer or the user's knowledge is power. But in order to keep a permanent copy of a copy to the hard disk will work. Then, through the printer or copy the written works of multimedia devices, video or audio tapes is an infringement of the author's intellectual property, if you download content into the public library is likely to lead to a lot of work to use and copy, reproduced or interconnect with each other online should be said is not prohibited by law. Although there are some web links and have been charged because of the case, such as "online ticket" website (Ticket Master). Total News, but the information sharing the spirit of the global information network will allow the prosecution is difficult to win. So at this stage to protect the legitimate interests of network operators and relations of the legitimate rights and interests, relying on "Copyright Law" cannot be achieved. In addition to implementing technology, control, sales contracts and entered into complete Instructions for Authors, relying on the deterrent power of the contract binding the parties is the only correct choice. Need to consider two issues:

1) Published on the right network. Network information to solve the most important intellectual property protection should be the basic issue is whether the network works of the law of "publish" request. Determine whether the infringement, to determine the solution, whether the "express" is a very important factor. In common law, the "published" is the formal public perception, and "published" are synonymous. In China, copyright law has been referred to a published work, copyright means the manner provided by copyright law known to the public of public works. Copyright protection is the author of the manifestation of ideas, not the idea itself. Online communication is a new technology, performance forms the ideological content of the author's originality and intellectual effort, is published in a form.

2) Reproduction rights. Dissemination of digital information through the network, the user on the display, by the user to download copy and print information on the network would constitute copying. China's "Copyright Law Implementing Regulations," that "copy. Refers to the printing, copying, copy, rubbing, audio, video, rip, Copy, etc. will produce one or more work behavior." So download, copy and print forms are copied, and displayed on a computer's random access memory is stored for display temporarily and does not copy a certain body, does not constitute a network of information replication.

A domain name is the user's address on the Internet, this address can be found through the company's home page and website is full of opportunities. Therefore, it is widely used for a business identification sign, as the basic means of developing e-commerce. Business firm as a domain name as a trademark in its advertising and extensive use of domain names, Internet domain names has become a business in the virtual world holds a status symbol. So the network domain name disputes involving trademarks be Wind and Smoke everywhere. Internet service providers to enjoy wins name dispute YAHOO even with the domain name trademark disputes the common nature of the network, the network was caused by Wall Street and the world's attention. In China, such as "Kelon" registered trademark and "Kelonocom.cn" domain names "and Wing Garment Factory" trademark, trade name rights infringement case is a typical representative.

Internet domain name disputes and trademark infringement disputes is the use of network information resources in the major infringement of intellectual property infringement. Of course, unfair competition disputes, intellectual property disputes, jurisdiction and responsibility of Internet 
service providers to define problems, but also the use of network information resources, is worth exploring.

Database development is the main bibliographic databases, abstracts, full text databases and database development. Bibliographic database development process does not involve copyright issues, mainly to respect the author's personal rights. In the production of abstracts database, you cannot obtain the copyright owner's permission, but must respect the right of authorship, while the corresponding compensation payment (Which in Article 32 of China's copyright law has been clearly stipulated that: work, once seen in the press, "In addition to the copyright owner has declared shall not be reproduced excerpts, other newspapers can be reproduced or as a digest of information published, but it should be in accordance with the provisions of the copyright pay compensation.”).The development of full-text database, in addition to the public domain works, the use of the work must be original copyright owner's permission.

Library as a public representative of the interests of copyright law in the country enjoy "immunity" or "exceptional" rights, that is within the law without the copyright owner's consent, without paying compensation, to use the rights of copyright works of others Although the fair use of digital libraries is still under the control of copyright, fair use is limited. However, while emphasizing the rational use, protection of intellectual property rights must be respected and properly handle the relationship with the interests of copyright owners. Only in this way to the rational use of digital libraries win a favorable policy and relaxed environment, thus contributing to the dissemination and sharing of information resources.

\section{The Rational Use of Information and Intellectual Property Protection Measures}

Intellectual property rights by giving exclusive rights to information to protect and mobilize the enthusiasm of the production and communicators, the protection of literary, artistic and scientific creativity and innovation, to promote the progress of science and art. Of network information resources must be protected, because otherwise people will not get the right to adequate return on investment and lose enthusiasm for the production of network information, the ability to create loss of information, information resources is not conducive to the production, development and utilization. In other words, not from the system to ensure that innovation actors should be the minimum compensation or benefits. The level of innovation is largely attributed to the continuous improvement of equity incentives. The so-called right to limit information is based on the creation of works of social attributes, in order to balance the rights of people, works of communicators and the public interest between the rights, the right people in the law the same rights and must fulfill certain obligations to society, that is the right person in the exercise of rights of the public should be allowed under the statutory conditions of use of its information system works, it is mainly through the rational use of the statutory licenses and compulsory licenses to achieve.

The use of network information resources and intellectual property protection is based on a balance of interests is still the principle that rights and the coordination between the public interest. Unilateral emphasis on protecting the rights or restrictions is not conducive to scientific, artistic progress and development. China's newly revised to adjust the rights of copyright law restrictions, but with the world standard of comparison, after adjustment provisions are still too broad, some are not specific, the process of administration of justice is not easy to grasp, in theory and practice need to be further improved.

The so-called collective management of intellectual property rights is the authorization of collective management of intellectual property rights of the unified management of their rights. Use of network information resources management of the particularity of individual rights makes more difficult, to say, the use of network information resources and communication channels between the rights is not smooth, but also the absence of such intermediaries. The newly revised "Copyright Law" Article VII: The State Council administrative department in charge the national copyright administration of copyright; provinces, autonomous regions and municipalities of the copyright administrative department in charge of the administrative district of copyright management. 
Article VIII: copyright owners and copyright-related right holders may authorize copyright collective management organization to exercise the copyright or copyright-related rights. Copyright collective management organization is authorized, you can own name as copyright owners and copyright-related right to argue the rights and can serve as a party involving copyright or rights related to copyright litigation, arbitration activities. Copyright collective management organization is a non-profit organization, its establishment way, rights and obligations, copyright royalty collection and distribution, as well as its supervision and management by the State Council separately.

Can be seen from the level of national legislation for the collective management organizations and made a clear normative position. Whether it is from the perspective of protecting the interests of right holders, or from the convenience of people, the establishment of efficient collective management organizations is very important. Therefore, we develop specific rules or regulations, they need to pay attention to absorb foreign advanced experience, and pay attention to China's national conditions.

1) Established network of information resources used in the network acts as one of the ways the use of works, network transmission are the copyright holder's exclusive rights. Work of network behavior, refers to the text (including computer programs), art, graphics, photography, movies and music and other works digitized through the network (including local area network) available to the public so the public can be chosen time and place and extent of exposure to the behavior of the aforementioned works. Network is one of the ways to use the work, are the exclusive rights of copyright holders. Others without license are not allowed to be transmitted to others online works proposed copyright law clearly states in our network the way for the use of the work. Hypertext links to transmit to the public works of the hinge should be identified as network behavior.

2) Established network of information resources used in the range of network behavior, legal responsibility and legal application. Works in the network transmission process to produce a series of actions involving intellectual property, which is prominent members of copying, such copying include: uploading, downloading, posting, forwarding, paste, save, digital, scan, view, print and so on. Who works as a transmission process of copying cannot be copied or behavior were identified, and are the perpetrator of violations of the copyright holder's right to bear legal responsibility for network transmission. When the users need to get permission to work, copy the behavior of the transmission process, as if to obtain a license. Although related to the Internet, but works independent of the transmission behavior of copying can still be identified as copying.

\section{Conclusions}

The Internet has greatly expanded the scope of the use of network information resources and scale, people search and ease of access to information resources and autonomy is also greatly enhanced, but also led to information sharing network of intellectual property protection and infringement issues. This article lists the use of network information resources and violations of copyright law and civil law from the perspective of legal thinking.

\section{References}

[1] http://www.cninpr.com/index.asp

[2] Ma haiqun. Network of information resources in the value of intellectual property protection and particularity of published studies, 2008-9

[3] Liu Huaying. Network environment information resources sharing intellectual property issues involved in analyzing intelligence magazine, 2003-12

[4] Sun Jie. Chinese system of legal protection of databases and development of comprehensive research library construction, 2003-6

[5] Guo Xiaolan. Process of information sharing early-warning mechanism of intellectual property infringement University Library, 2003-3 